Article

\title{
Synthesis and Characterization of Constrained Geometry Oxygen and Sulphur Functionalized Cyclopentadienylchromium Complexes and Their Use in Catalysis for Olefin Polymerization
}

\author{
Ruiguo Zhao ${ }^{1,2}$, Jun $\mathrm{Ma}^{2}$, Hao Zhang ${ }^{1,2, *}$ and Jiling Huang ${ }^{2, *}$ \\ 1 School of Chemistry and Chemical Engineering, Inner Mongolia University, Hohhot 010021, China; \\ zhaoruig@imu.edu.cn \\ 2 The Laboratory of Organometallic Chemistry, East China University of Science and Technology, \\ Shanghai 200237, China; majun197906@sohu.com \\ * Correspondence: haozhang@imu.edu.cn (H.Z.); jlhuang@ecust.edu.cn (J.H.); \\ Tel.: +86-0471-499-4406 (H.Z.); +86-021-6425-3519 (J.H.)
}

Academic Editor: Kotohiro Nomura

Received: 11 April 2017; Accepted: 15 May 2017; Published: 22 May 2017

\begin{abstract}
A series of constrained geometry O-functionalized cyclopentadienylchromium complexes (1-6) and a S-functionalized cyclopentadienylchromium complex (7) were first synthesized, characterized, and tested as catalyst precursors for the olefin polymerization. In the presence of MAO, the complexes exhibited high catalytic activity for the polymerization of ethylene. It is shown that ligand variations can have a substantial effect on catalyst activity and stability. The effect of $\mathrm{Al} / \mathrm{Cr}$ ratio on catalytic activity was also studied.
\end{abstract}

Keywords: CGC-organochromium complexes; oxygen functionalized cyclopentadienyl; olefin polymerization

\section{Introduction}

Olefin polymerization by homogeneous transition metal complex catalysts attracts particular attention in the field of organometallic chemistry, catalysis, and polymer chemistry. Many reports have focused on the use of various transition metal complexes [1-5]. Chromium catalysts played a key role in the early development of heterogeneous catalysts for the polymerization of alkenes. It has been well known that the chromium-based heterogeneous catalysts, such as Phillips catalysts $\left(\mathrm{Cr}_{2} \mathrm{O}_{3} / \mathrm{SiO}_{2}\right)[6]$ and the Union Carbide Unipol catalysts $\left(\mathrm{Cp}_{2} \mathrm{Cr} / \mathrm{SiO}_{2}\right)[7,8]$, have been used in industrial production of high-density polyethylene (HDPE) since the 1950s. Contrary to the Ziegler-Natta system, few studies have reported on the mechanism and nature of the active species in these chromium catalytic systems. It is mainly because the chemistry of $\mathrm{Cr}(\mathrm{III})$ is particularly difficult to study as a result of its paramagnetic nature. In recent years, some of the most significant advances in $\mathrm{Cp}$-based chromium catalyst systems have been made using precatalysts that bear an additional neutral donor and bridged the Cp unit [9-25], so-called CGC system (CGC = Constrained Geometry Catalyst). They have already been used as efficient catalyst precursors for ethylene or 1-hexene homo (co)-polymerization, which are listed in Figure 1. However, only a couple of reports concerning O-functionalized Cp-based chromium catalyst have been published [10]. 
<smiles>[X]C1([X])C2C=CC(C2)N1C(C)C</smiles>

a

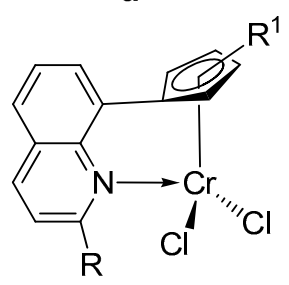

e

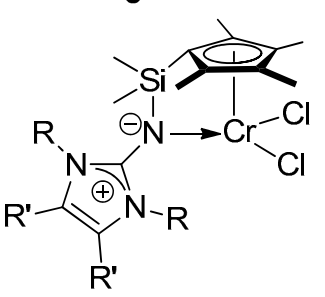<smiles>[X]C1C2CCN([R2])C([X])(C1[R])C2[R]</smiles>

b

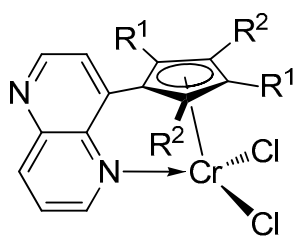

f

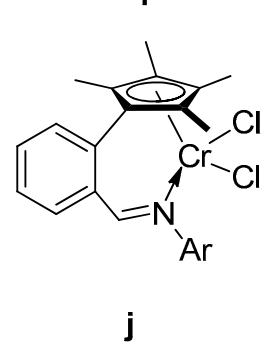<smiles></smiles>

C<smiles>CC1=C(C)C2(C)C(C)=C(C)C(C)(c3ccccc31)C(Cl)(Cl)N2C</smiles>

g

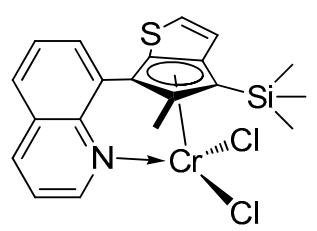

k

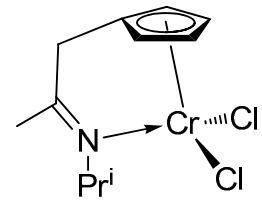

d<smiles>[R]C1C2CC[R]([R])([R])C1([X])C2[R]</smiles>

h

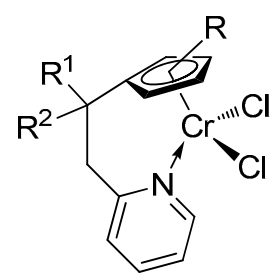

I

Figure 1. Constrained geometry Cyclopentadienylchromium Complexes.

Since 1985, our group has been devoted to the research of O-containing Ti, Zr complexes. In our previous work, we introduced methoxyl ethyl, tetrahydrofurfuryl, and ortho-methoxyl benzyl type groups to the $\mathrm{Cp}$ (Ind) ligand, and found they showed a good tendency to form a chelate structure under moderate conditions in the synthesis of corresponding Ti, Zr complexes (Figure 2) [3,26-29].<smiles></smiles><smiles>Cl[Te]1(Cl)(Cl)(Cl)OC2CCCC1C2</smiles><smiles></smiles><smiles>COC(C)CC1CCC1[I+](Cl)(Cl)Cl</smiles><smiles>COCCCC1=CC=C1[Te](Cl)(Cl)Cl</smiles>
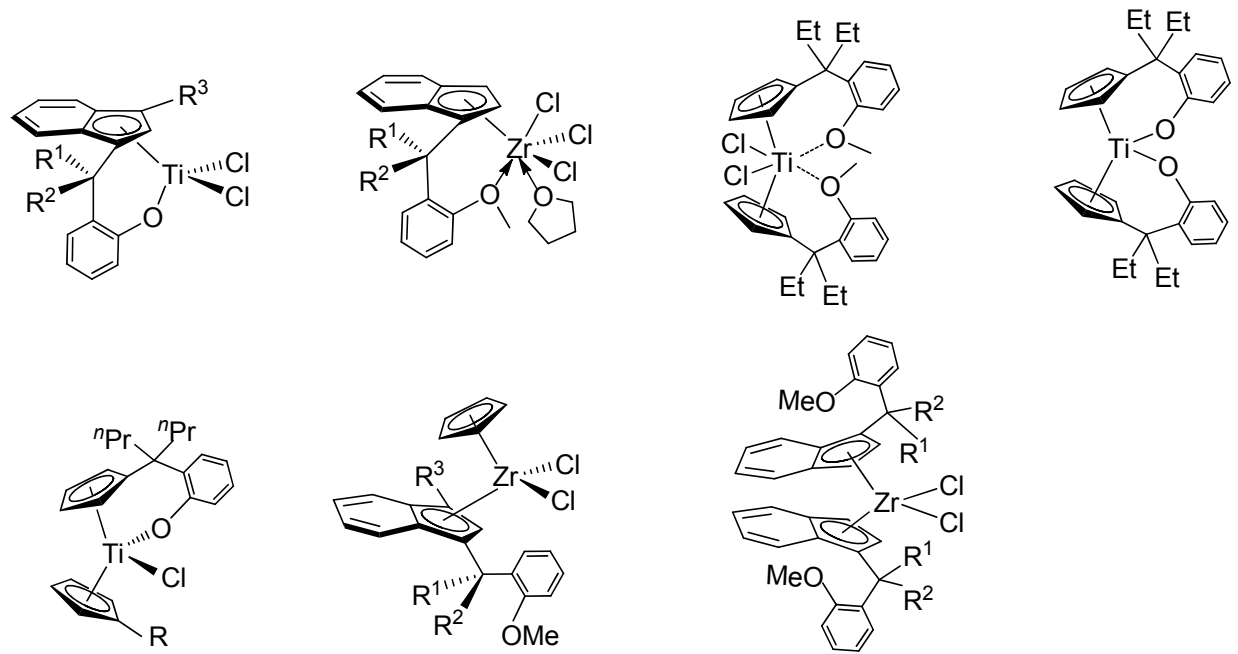

Figure 2. Ti, Zr complexes were reported by our group. 
With regard to the relevance to the above Cp-based chromium catalyst and our primary interest [25], we are interested in exploring the possibility of O-functionalized and S-functionalized cyclopentadienylchromium complexes as the olefin polymerization catalyst. Here, we describe the synthesis of a range of O-functionalized and S-functionalized cyclopentadienylchromium complexes catalysts and evaluate the effect of variations in the ligand system on the performance in ethylene polymerization catalysis.

In this paper, we wish to discuss the synthesis, structure and olefin polymerization details of novel ortho-methoxyl benzyl, furyl, and the thiofuryl substituted cyclopentadienylchromium complex. As a result of these studies, a proposal for the pathways of generation and action of the species responsible for the ethene polymerization could be formulated, and catalysts have been obtained that can produce $>100 \mathrm{~kg}$ of ethene polymerization product/(mol of $\mathrm{Cr}$ ) under moderate conditions.

\section{Results}

\subsection{Synthesis and Characterization of Chromium Complexes}

The route of the synthesis of the ortho-methoxyl benzyl substituted cyclopentadienyl chromium complex 1-3 is summarized in Scheme 1. The ortho-methoxyl benzyl substituted cyclopentadienyl ligand is readily obtainable from the reaction of 6,6-dialkylfulvene with the appropriate ortho-methoxyl benzyl lithium salts [27]. The reaction of these ligands with $\mathrm{CrCl}_{3}(\mathrm{THF})_{3}$ leads to the half-sandwich chromium complexes 1-3, which were isolated in moderate yield. The IR spectra of these complexes also prove that the oxygen atom is coordinated to the chromium atom (see Supplementary Materials).

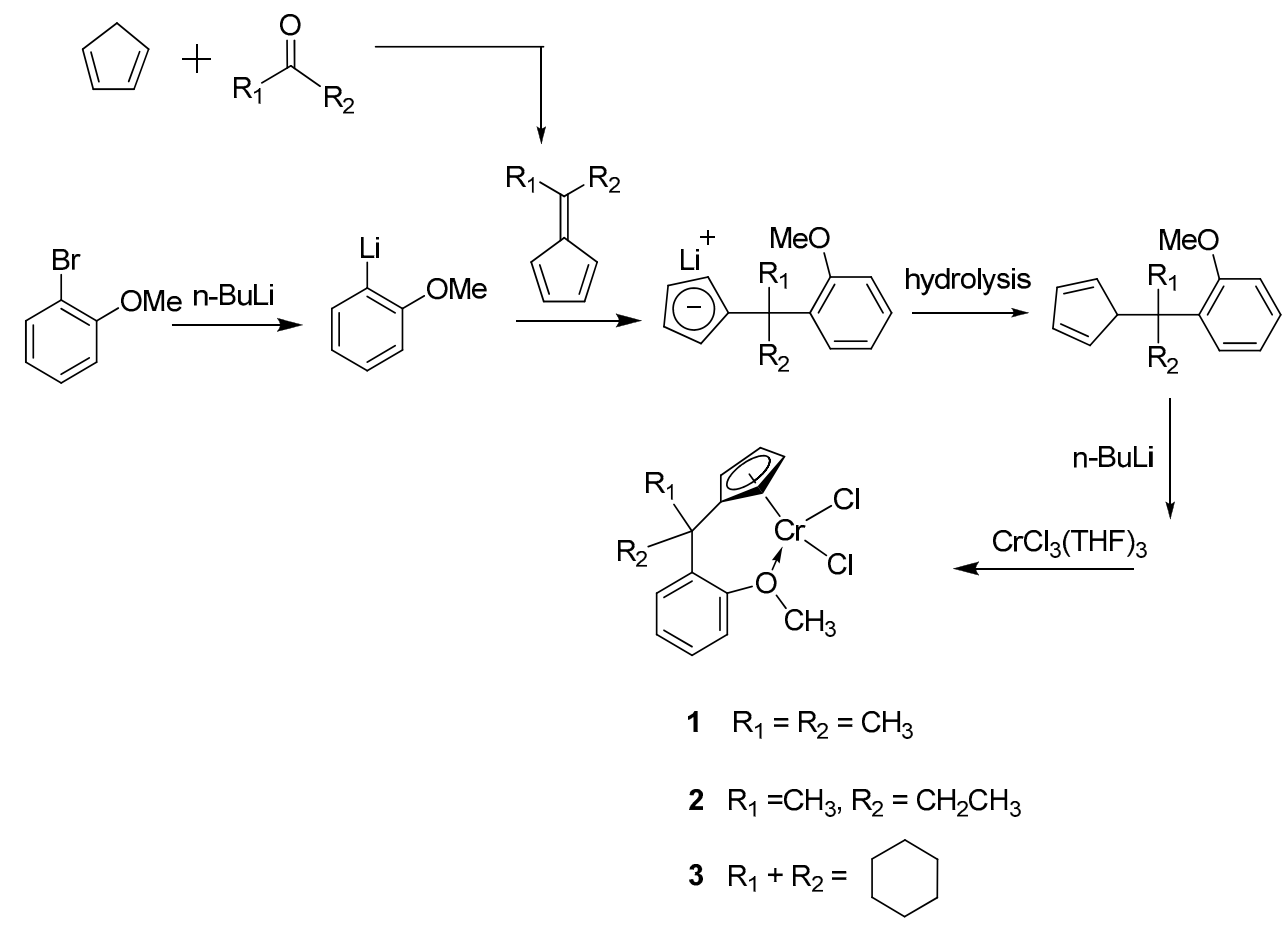

Scheme 1. Route of the synthesis of cyclopentadienylchromium complexes 1-3.

The routes employed for the synthesis of the furyl and the thiofuryl substituted cyclopentadienylchromium complexes are summarized in Scheme 2. These ligands were readily obtainable from the reaction of 6,6-dialkylfulvene with the appropriate furyl or thiofuryl lithium salts $[27,29]$. 


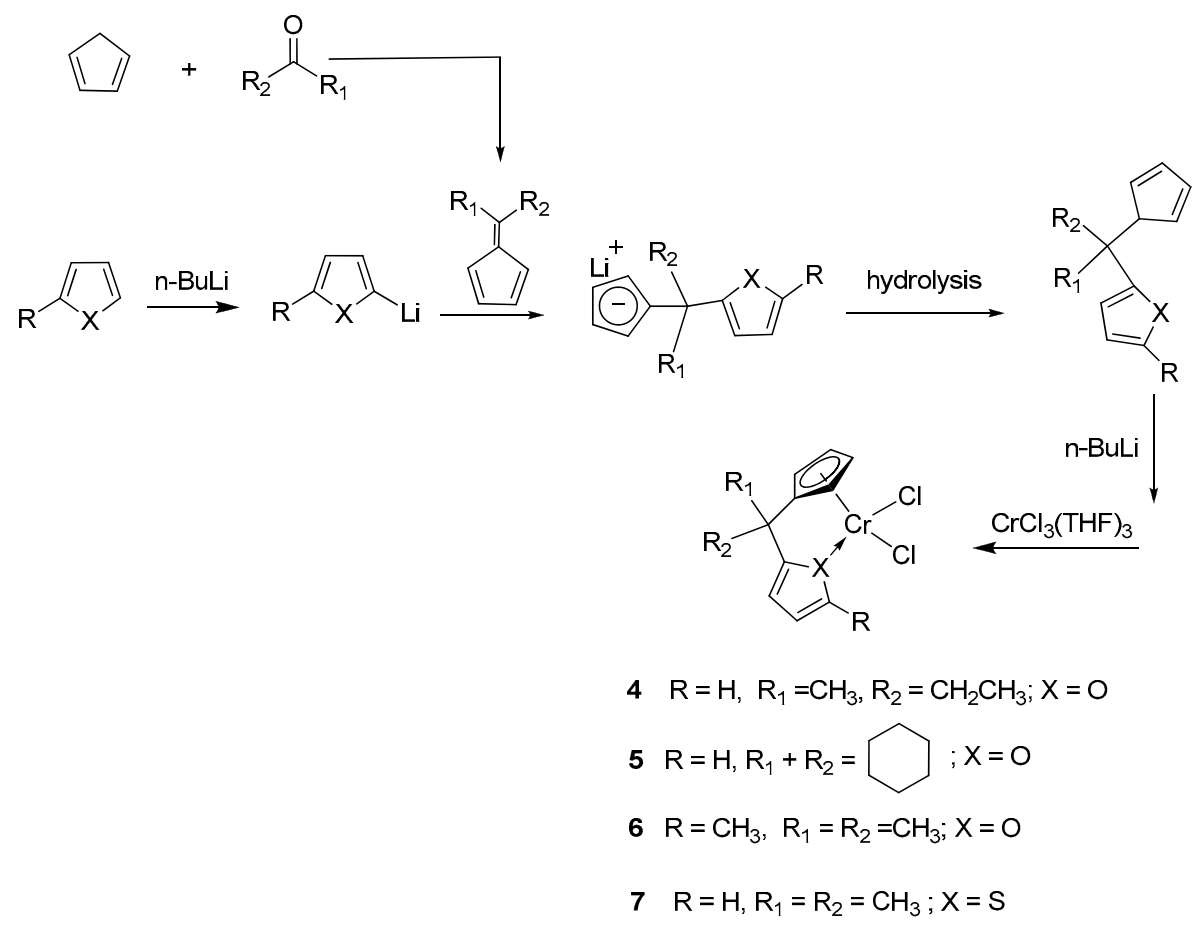

Scheme 2. Route of the synthesis of cyclopentadienylchromium complexes 4-7.

\subsection{Polymerization of Olefin Use $\mathbf{1}-\mathbf{7}$}

The ethylene polymerization results using complexes $1,2,3,4,5,6$, and 7 as catalyst precursor in the presence of MAO are shown in Table 1 . The catalytic activities of complexes 1, 2, 4, and $\mathbf{6}$ were similar to those of $\mathrm{Cp}_{2} \mathrm{TiCl}_{2}$ e.g., $10^{5} \mathrm{gPE} / \mathrm{mol} \mathrm{M} \cdot \mathrm{h}$. In addition, the catalytic activities of complex 7 were similar to those of $\mathrm{Cp}_{2} \mathrm{ZrCl}_{2}$, e.g., $10^{6} \mathrm{gPE} / \mathrm{mol} \mathrm{M} \cdot \mathrm{h}$. Among them, complex 7 showed the highest activity as $1.96 \times 10^{6} \mathrm{gPE} / \mathrm{mol} \mathrm{Cr} \cdot \mathrm{h}$ for ethylene polymerization. The ligand structure and the molar ratio of $\mathrm{Al} / \mathrm{Cr}$ influence both the activities of the complexes and the molecular weights of resultant polyethylenes.

The data in Table 1 demonstrate that the steric and electronic effects of the substituents on side chain of cyclopentadienyl the ligand exert significant influence on the catalytic activities of these complexes. Complexes 1, 2 and 4, 6 with ortho-methoxyl benzyl and furyl on side chain of the cyclopentadienyl show much lower activities than complex 7 with thiofuryl substituents for ethylene polymerization under same conditions (entries 3, 4, 13, 14 versus entries 15, 16), suggesting that the electronic effect of the substituents may have played a significant role in ethylene polymerization. This may be due to the coordination atom from $\mathrm{O}$ to $\mathrm{S}$ which makes the coordination capacity of coordination atom increase and the corresponding complex catalytic activity increases as a result. At the same time, with the increase of the steric hindrance on the side chain carbon bridge of complexes $\mathbf{1}$ and 2, an obvious increase of the catalytic activity is observed when double Me groups are replaced by $M e$ and $E t$ groups. The increase in the steric hindrance on the carbon bridge may be more favorable for the coordination of the suspended group with the metal center [29]. However, the space effect of side chain of the cyclopentadienyl ring is inverted for cyclohexyl substituted complexes $\mathbf{3}$ and $\mathbf{5}$. We speculate that this may be because the role of carbon bridge steric hindrance is too large so that the coordination space of the catalytic activity center is too congested and it is difficult for ethylene to insert, which results in a decrease of the catalytic activity.

It is found that the molecular weights of the resultant polymers are closely dependent on the structure of the catalysts. In general, the increase of the steric hindrance of the substituents in the ligand framework results in a decrease of the molecular weights of the obtained polymers. For example, 
under the polymerization conditions of $\mathrm{Al} / \mathrm{Ti}=1000$ and 2000, with the variation of the substituent of side chain the cyclopentadienyl ring from double $M e(\mathbf{1})$ to $M e$ and $E t$ (2), a decrease of $M_{\eta}$ values of the resulted polyethylenes from $8.96 \sim 5.62 \times 10^{4} \mathrm{~g} / \mathrm{mol}$ to $7.73 \sim 4.40 \times 10^{4} \mathrm{~g} / \mathrm{mol}$ could be observed (entries 3, 4, 5, 6, respectively). GPC measurement of a polymer sample obtained with complex 7 indicated $M_{\mathrm{n}}=4.92 \times 104 \mathrm{~g} / \mathrm{mol}$ with $M_{\mathrm{w}} / M_{\mathrm{n}}=1.89$ (entry 16 in Table 1). Moreover, the obtained PEs possesses melting points in the range $133-135^{\circ} \mathrm{C}$, typical for linear polyethylene. [30,31]

As observed for most of the catalytic olefin polymerization systems, the activity of these chromium complexes toward ethylene polymerization is also influenced by the molar ratio of $\mathrm{Al} / \mathrm{Cr}$. With the increase of $\mathrm{Al} / \mathrm{Cr}$ ratio from 1000 to 2000, the activity of complex 7 is increased from $1.10 \times 10^{6} \mathrm{~g}$ $\mathrm{PE} / \mathrm{mol} \mathrm{Cr} \cdot \mathrm{h}$ to $1.96 \times 10^{6} \mathrm{~g} \mathrm{PE} / \mathrm{mol} \mathrm{Cr} \cdot \mathrm{h}$ (entries 15 and 16). A similar trend is also found for the other complexes. The influence of the $\mathrm{Al} / \mathrm{Cr}$ molar ratio on the polymer molecular weights was also investigated. The results shown in Table 1 indicate that, in general, under the same conditions, the molecular weight of the obtained $\mathrm{PE}$ decreases with the increase of the $\mathrm{Al} / \mathrm{Cr}$ molar ratio. From the ${ }^{1} \mathrm{H}-\mathrm{NMR}$ spectrum of a typical polyethylene sample obtained with 7, (see Supplementary Materials) no obvious alkenyl hydrogen signals could be detected, implying that the dominant termination process is chain transfer to aluminum instead of the $\beta$-hydride elimination reaction [31,32].

Table 1. Polymerizations of ethylene using cyclopentadienylchromium complex $1-7^{\mathrm{a}}$.

\begin{tabular}{|c|c|c|c|c|c|c|}
\hline Entry & $\begin{array}{c}\text { Cat. } \\
\text { (amt of } M(\mu \mathrm{mol}))\end{array}$ & $\mathbf{A l} / \mathbf{M}$ & $\begin{array}{l}\text { PE } \\
(\mathrm{mg})\end{array}$ & $\begin{array}{c}\text { Activity } \\
\left(10^{5} \mathrm{~g} /(\mathrm{mol}-\mathrm{M} \cdot \mathrm{h})\right)\end{array}$ & $\begin{array}{c}M_{\eta} \mathrm{b} \\
\left(10^{4} \mathrm{~g} / \mathrm{mol}\right)\end{array}$ & $\begin{array}{l}T_{\mathrm{m}} / T_{\mathrm{c}}{ }^{\mathrm{c}} \\
\quad\left({ }^{\circ} \mathrm{C}\right)\end{array}$ \\
\hline 1 & $\mathrm{Cp}_{2} \mathrm{TiCl}_{2}(5.05)$ & 1000 & 725 & 2.87 & - & - \\
\hline 2 & $\mathrm{Cp}_{2} \mathrm{ZrCl}_{2}(5.05)$ & 1000 & 4090 & 16.2 & - & - \\
\hline 3 & $\mathbf{1}(5.05)$ & 1000 & 66 & 0.39 & 8.96 & $133.4 / 109.7$ \\
\hline 4 & $1(5.05)$ & 2000 & 326 & 1.29 & 5.62 & $134.6 / 110.5$ \\
\hline 5 & $2(5.05)$ & 1000 & 169 & 0.67 & 7.73 & $133.7 / 110.2$ \\
\hline 6 & $2(5.05)$ & 2000 & 804 & 3.19 & 4.40 & 132.5/109.1 \\
\hline 7 & $3(5.05)$ & 1000 & 30 & 0.12 & - & - \\
\hline 8 & $3(5.05)$ & 2000 & 40 & 0.16 & - & - \\
\hline 9 & $4(5.05)$ & 1000 & 286 & 1.16 & 15.8 & $135.2 / 110.8$ \\
\hline 10 & $4(5.05)$ & 2000 & 1619 & 6.41 & 6.88 & $134.5 / 111.9$ \\
\hline 11 & $5(2.39)$ & 1000 & 13 & 0.18 & - & - \\
\hline 12 & $5(2.39)$ & 2000 & 20 & 0.11 & - & - \\
\hline 13 & $6(2.10)$ & 1000 & 153 & 1.46 & 10.8 & $133.2 / 109.5$ \\
\hline 14 & $6(2.10)$ & 2000 & 544 & 5.18 & 6.74 & $133.6 / 109.2$ \\
\hline 15 & $7(2.89)$ & 1000 & 1593 & 11.0 & 14.0 & $134.2 / 110.7$ \\
\hline 16 & $7(2.89)$ & 2000 & 2834 & 19.6 & $8.32^{\mathrm{d}}$ & $134.7 / 111.3$ \\
\hline
\end{tabular}

a Conditions: toluene as solvent, $V_{\text {total }}=50 \mathrm{~mL}$, Temp. $=25^{\circ} \mathrm{C}, \mathrm{MAO}$ as cocatalyst, $0.2 \mathrm{MPa}$ of ethylene, $30 \mathrm{~min}$;

$\mathrm{b}$ Intrinsic viscosity was determined in decahydronaphthalene at $135^{\circ} \mathrm{C}$ by Ubbelohde viscometer technique, and the viscosity average molecular weights were calculated using the relation [33]: $[\eta]=6.67 \times 10^{-4} M_{\eta}{ }^{0.67}$, in unit of $10^{4} \mathrm{~g} / \mathrm{mol} ;{ }^{\mathrm{c}}$ Determined by DSC at a heating rate of $10^{\circ} \mathrm{C} \mathrm{min}^{-1} ;{ }^{\mathrm{d}} M_{\mathrm{W}}$ and $M_{\mathrm{w}} / M_{\mathrm{n}}$ were determined by GPC, using 1 ,2-dichlorobenzene as solvent at $140{ }^{\circ} \mathrm{C}$, in unit of $10^{4} \mathrm{~g} / \mathrm{mol}$. For entry $16, M_{\mathrm{W}}=4.92 \times 10^{4} \mathrm{~g} / \mathrm{mol}, M_{\mathrm{w}} / M_{\mathrm{n}}=1.89$.

\section{Materials and Methods}

\subsection{General Experimental Procedures}

All operations were carried out under an argon atmosphere using the standard Schlenk techniques. Tetrahydrofuran (THF), diethyl ether, toluene, and n-hexane were freshly distilled from sodium benzophenone ketyl under argon prior to use. Methylene chloride was distilled over $\mathrm{P}_{2} \mathrm{O}_{5}$ and $\mathrm{CaH}_{2}$ under nitrogen. Methylaluminoxane (MAO) was purchased from Wittco (Baltimore, MD, USA).

All complexes were characterized by FT-IR, EA, and MS. ${ }^{1} \mathrm{H}-\mathrm{NMR}$ spectrum of typical polymer sample was recorded on a GRMINI-400 NMR spectrometer (Varian, Palo Alto, CA, USA) at $100{ }^{\circ} \mathrm{C}$ using a mixture solvent of $o$-dichlorobenzene and $\mathrm{C}_{6} \mathrm{D}_{6}(4: 1)$. IR spectra were recorded on a Nicolet MAGNA-IR 550 spectrometer (Thermo Fisher Scientific, Waltham, MA, USA) as KBr pellets. Mass spectra were obtained at $70 \mathrm{eV}$ using a HP 5989A mass spectrometer. Elemental analyses were performed on an EA-1106 spectrometer. 


\subsection{Synthesis of Complexes $\mathbf{1 - 7}$}

Synthesis of complex 1: Ligand 1a was prepared according to the literature [27]. To a solution of $2.13 \mathrm{~g}(10.0 \mathrm{mmol})$ ligand 1a in $20 \mathrm{~mL}$ THF in the flask, a solution of butyl lithium $8.19 \mathrm{~mL}(1.22 \mathrm{~mol} / \mathrm{L}$, $10.0 \mathrm{mmol}$ ) in THF was dropwise added at $-78{ }^{\circ} \mathrm{C}$. After complete addition the reaction mixture was stirred for $12 \mathrm{~h}$. Then the resulting solution was added to the suspension of $\mathrm{CrCl}_{3}(\mathrm{THF})_{3} 3.71 \mathrm{~g}$ $(10.0 \mathrm{mmol})$ in $45 \mathrm{~mL}$ of THF at $-78^{\circ} \mathrm{C}$. The mixture was stirred overnight. The color of the reaction mixture changed from purple to blue then to dark green. After the solvent was removed under vacuum, toluene was added to precipitate $\mathrm{LiCl}$, and the organic layer was concentrated to $30 \mathrm{~mL}$. At low temperature, $0.46 \mathrm{~g}$ dark green crystals were obtained in 13.6\% yield. EI-MS (m/e): 335 (75, M), 300 (100, M-Cl), 264 (52, M-2Cl), 235 (5, M-2CH $-2 \mathrm{Cl}), 213$ (12, M-2Cl-Cr), 198 (11, M-CH $3-2 \mathrm{Cl}-\mathrm{Cr}$ ), 183 (13, M-2CH $\left.\mathrm{CH}_{3}-\mathrm{HCl}-\mathrm{Cr}\right), 108$ (47, $\left.\mathrm{PhOCH}_{3}\right)$. IR( $\left.\mathrm{cm}^{-1}, \mathrm{KBr}\right): 3109$ m, $3092 \mathrm{~m}, 3070$ w, 2995 m, 2960 m, 2875 w, 1482 s, 1447 s, 1405 w, 1363 m, 1287 m, 1241 m, 1206 m, 1155 m, 1136 m, 1080 m, 1047 w, 1032 m, 973 s, 933 w, 839 s, 798 s, 761 s, 694 m. Calc. for $\mathrm{C}_{15} \mathrm{H}_{17} \mathrm{Cl}_{2} \mathrm{CrO}: \mathrm{C}, 53.59 \%$; H, 5.10\%. Found: $\mathrm{C}$, $53.11 \% ; \mathrm{H}, 5.16 \%$. HRMS Calc. for $\mathrm{C}_{15} \mathrm{H}_{17} \mathrm{Cl}_{2} \mathrm{CrO}=335.0063$. Found: $\mathrm{C}_{15} \mathrm{H}_{17} \mathrm{Cl}_{2} \mathrm{CrO}=335.0062$.

Synthesis of complex 2: Ligand 2a was prepared according to the literature [27]. To a solution of $2.27 \mathrm{~g}(10.0 \mathrm{mmol})$ ligand $2 \mathrm{a}$ in $20 \mathrm{~mL}$ THF in the flask, a solution of butyl lithium $8.19 \mathrm{~mL}(1.22 \mathrm{~mol} / \mathrm{L}$, $10.0 \mathrm{mmol}$ ) in THF was dropwise added at $-78{ }^{\circ} \mathrm{C}$. After complete addition the reaction mixture was stirred for $12 \mathrm{~h}$. Then the resulting solution was added to the suspension of $\mathrm{CrCl}_{3}(\mathrm{THF})_{3} 3.56 \mathrm{~g}$ (9.58 mmol) in $45 \mathrm{~mL}$ of THF at $-78^{\circ} \mathrm{C}$. The mixture was stirred overnight. The color of the reaction mixture changed from purple to blue then to dark green. After the solvent was removed under vacuum, toluene was added to precipitate $\mathrm{LiCl}$, and the organic layer was concentrated to $30 \mathrm{~mL}$. At low temperature, $1.18 \mathrm{~g}$ dark green crystals were obtained in 35.0\% yield. EI-MS (m/e): 349 (100, M), 314 (59, M-Cl) 279 (15, M-2Cl), 250 (6, M-2Cl-Et), 227 (10, M-2Cl-Cr), 198 (11, M-CH ${ }_{3}-2 \mathrm{Cl}-\mathrm{Cr}$ ), 183 (13, M-2CH $3-2 \mathrm{Cl}-\mathrm{Cr}), 108$ (4, $\left.\mathrm{PhOCH}_{3}\right)$. IR (cm $\left.{ }^{-1}, \mathrm{KBr}\right): 3112$ w, 3097 s, 3043 w, 2973 s, 2937 w, 2878 w, 1602 w, $1580 \mathrm{w}, 1484 \mathrm{~s}, 1468 \mathrm{~s}, 1452 \mathrm{~s}, 1407 \mathrm{~m}, 1383 \mathrm{w}, 1214 \mathrm{~m}, 1162 \mathrm{~m}, 1150 \mathrm{~m}, 1127 \mathrm{w}, 1088$ m, 1048 m, $1033 \mathrm{~m}$, 967 s, 940 w, 827 s, 794 m, 770 s, 753 m, 695 m. Calc. for $\mathrm{C}_{16} \mathrm{H}_{19} \mathrm{Cl}_{2} \mathrm{CrO}$ : C, 54.87\%; H, 5.47\%. Found: C, $54.64 \% ; \mathrm{H}, 5.50 \%$. HRMS Calc. for $\mathrm{C}_{16} \mathrm{H}_{19} \mathrm{Cl}_{2} \mathrm{CrO}=349.0218$. Found: $\mathrm{C}_{16} \mathrm{H}_{19} \mathrm{Cl}_{2} \mathrm{CrO}=349.0215$.

Synthesis of complex 3: Ligand 3a was prepared according to the literature [27]. To a solution of $1.28 \mathrm{~g}(5.04 \mathrm{mmol})$ ligand 3a in $20 \mathrm{~mL}$ THF in the flask, a solution of butyl lithium $4.13 \mathrm{~mL}(1.22 \mathrm{~mol} / \mathrm{L}$, $5.04 \mathrm{mmol}$ ) in THF was dropwise added at $-78{ }^{\circ} \mathrm{C}$. After complete addition, the reaction mixture was stirred for $12 \mathrm{~h}$. Then the resulting solution was added to the suspension of $\mathrm{CrCl}_{3}(\mathrm{THF})_{3} 1.87 \mathrm{~g}$ $(5.04 \mathrm{mmol})$ in $45 \mathrm{~mL}$ of THF at $-78^{\circ} \mathrm{C}$. The mixture was stirred overnight. The color of the reaction mixture changed from purple to blue then to dark blue. After the solvent was removed under vacuum, toluene was added to precipitate $\mathrm{LiCl}$, and the organic layer was concentrated to $30 \mathrm{~mL}$. At low temperature, $0.32 \mathrm{~g}$ dark blue needle crystals were obtained in $16.9 \%$ yield. EI-MS (m/e): $375(1, \mathrm{M})$, 340 (17, M-Cl), 291 (14, M-2Cl-CH $\left.{ }_{3}\right), 219\left(4, \mathrm{M}-\mathrm{CH}_{3}-2 \mathrm{Cl}-\left(\mathrm{CH}_{2}\right)_{5}\right) . \mathrm{IR}\left(\mathrm{cm}^{-1}, \mathrm{KBr}\right): 3092 \mathrm{~m}, 3107 \mathrm{~m}$, 3029 w, 2970 m, 2920 s, 2855 m, 2829 w, 1637 s, 1480 s, 1460 w, 1435 w, 1407 m, 1368 m, 1137 m, 1074 m, 1040 s, 921 m, 827 s, 725 m, 651 m. Calc. for $\mathrm{C}_{18} \mathrm{H}_{21} \mathrm{Cl}_{2} \mathrm{CrO}$ : C, 57.46\%; H, 5.63\%. Found: C, 56.99\%; H, 5.40\%. HRMS Calc. for $\mathrm{C}_{18} \mathrm{H}_{21} \mathrm{Cl}_{2} \mathrm{CrO}=375.0375$. Found: $\mathrm{C}_{18} \mathrm{H}_{21} \mathrm{Cl}_{2} \mathrm{CrO}=375.0394$.

Synthesis of complex 4: Ligand 4a was prepared according to the literature [27]. To a solution of $0.93 \mathrm{~g}(4.30 \mathrm{mmol})$ ligand $4 \mathrm{a}$ in $20 \mathrm{~mL}$ THF in the flask, a solution of butyl lithium $3.80 \mathrm{~mL}(1.22 \mathrm{~mol} / \mathrm{L}$, $4.30 \mathrm{mmol}$ ) in THF was dropwise added at $-78{ }^{\circ} \mathrm{C}$. After complete addition the reaction mixture was stirred for $12 \mathrm{~h}$. Then the resulting solution was added to the suspension of $\mathrm{CrCl}_{3}(\mathrm{THF})_{3} 1.61 \mathrm{~g}$ ( $4.30 \mathrm{mmol}$ ) in $45 \mathrm{~mL}$ of THF at $-78^{\circ} \mathrm{C}$. The mixture was stirred overnight. The color of the reaction mixture changed from purple to blue then to dark blue. After the solvent was removed under vacuum, toluene was added to precipitate $\mathrm{LiCl}$, and the organic layer was concentrated to $30 \mathrm{~mL}$. At low temperature, $0.36 \mathrm{~g}$ dark blue needle crystals were obtained in 27.1\% yield. EI-MS (m/e): 309 (29, M),

273 (28, M-Cl), 244 (100, M- O'), 239 (7, M-2Cl). IR (cm-1, KBr): 3112 m, 3096 m, 2970 s, 2931 m, 2878 
m, 1613 w, 1502 m, 1468 m, 1414 m, 1381 w, 1261 m, 1159 s, 1105 m, 1049 m, 1014 s, 921 m, 838 s, 805 w, 724 s, 598 m. Calc. for $\mathrm{C}_{13} \mathrm{H}_{15} \mathrm{Cl}_{2} \mathrm{CrO}$ : C, 50.34\%; H, 4.87\%. Found: C, 50.21\%; H, 5.03\%.

Synthesis of complex 5: Ligand 5a was prepared according to the literature [27]. To a solution of $0.93 \mathrm{~g}$ ( $4.3 \mathrm{mmol})$ ligand $5 \mathrm{a}$ in $20 \mathrm{~mL}$ THF in the flask, a solution of butyl lithium $3.80 \mathrm{~mL}(1.22 \mathrm{~mol} / \mathrm{L}$, $4.3 \mathrm{mmol}$ ) in THF was dropwise added at $-78{ }^{\circ} \mathrm{C}$. After complete addition the reaction mixture was stirred for $12 \mathrm{~h}$. Then the resulting solution was added to the suspension of $\mathrm{CrCl}_{3}(\mathrm{THF})_{3} 1.61 \mathrm{~g}$ $(4.3 \mathrm{mmol})$ in $45 \mathrm{~mL}$ of $\mathrm{THF}$ at $-78{ }^{\circ} \mathrm{C}$. The mixture was stirred overnight. The color of the reaction mixture changed from purple to blue then to dark blue. After the solvent was removed under vacuum, toluene was added to precipitate $\mathrm{LiCl}$, and the organic layer was concentrated to $30 \mathrm{~mL}$. At low temperature, $23.1 \mathrm{mg}$ dark blue needle crystals were obtained in 16.1\% yield. EI-MS (m/e): 335 (67, M), 299 (100, M-Cl), 261 (51, M-2Cl), 214 (34, M-2Cl-Cr). IR (cm $\left.{ }^{-1}, \mathrm{KBr}\right): 3134$ w, 3107 m, 2934 s, 2856 m, 1656 w, 1637 w, 1623 w, 1496 m, 1461 m, 1409 m, 1223 w, 1198 w, 1156 m, 1114 w, 1045 w, 1012 m, 936 w, 885 w, 830 s, 748 s, 598 w, 503 w, 423 w. Calc. for $\mathrm{C}_{15} \mathrm{H}_{17} \mathrm{Cl}_{2} \mathrm{CrO}$ : C, 53.59\%; H, 5.10\%. Found: C, 53.20\%; H, 5.22\%.

Synthesis of complex 6: Ligand 6 a was prepared according to the literature [27]. To a solution of $0.93 \mathrm{~g}$ (4.3 mmol) ligand $\mathbf{6 a}$ in $20 \mathrm{~mL}$ THF in the flask, a solution of butyl lithium $3.80 \mathrm{~mL}(1.22 \mathrm{~mol} / \mathrm{L}$, $4.3 \mathrm{mmol}$ ) in THF was dropwise added at $-78^{\circ} \mathrm{C}$. After complete addition the reaction mixture was stirred for $12 \mathrm{~h}$. Then the resulting solution was added to the suspension of $\mathrm{CrCl}_{3}(\mathrm{THF})_{3} 1.61 \mathrm{~g}$ $(4.3 \mathrm{mmol})$ in $45 \mathrm{~mL}$ of THF at $-78^{\circ} \mathrm{C}$. The mixture was stirred overnight. The color of the reaction mixture changed from purple to blue then to dark blue. After the solvent was removed under vacuum, toluene was added to precipitate $\mathrm{LiCl}$, and the organic layer was concentrated to $30 \mathrm{~mL}$. At low temperature, $23.1 \mathrm{mg}$ dark blue needle crystals were obtained in 16.1\% yield. EI-MS (m/e): 309 (13, M), 273 (100, M-Cl), 239 (21, M-2Cl), 187 (13, M-2Cl-Cr). IR (cm $\left.{ }^{-1}, \mathrm{KBr}\right): 3104 \mathrm{~s}, 2975$ s, 2935 m, 2875 m, 1608 m, 1552 m, 1477 m, 1447 w, 1409 m, 1242 m, 1217 m, 1108 s, 1043 m, 1023 m, 958 m, 835 s, 786 s, 679 w. Calc. for $\mathrm{C}_{13} \mathrm{H}_{15} \mathrm{Cl}_{2} \mathrm{CrO}$ : C, 50.34\%; H, 4.87\%; Found: C, 51.04\%; $\mathrm{H}, 5.07 \%$.

Synthesis of complex 7: Ligand 7a was prepared according to the literature [29]. To a solution of $0.73 \mathrm{~g}(3.7 \mathrm{mmol})$ ligand $7 \mathrm{a}$ in $20 \mathrm{~mL}$ THF in the flask, a solution of butyl lithium $2.9 \mathrm{~mL}(1.22 \mathrm{~mol} / \mathrm{L}$, $3.7 \mathrm{mmol}$ ) in THF was dropwise added at $-78{ }^{\circ} \mathrm{C}$. After complete addition the reaction mixture was stirred for $12 \mathrm{~h}$. Then the resulting solution was added to the suspension of $\mathrm{CrCl}_{3}(\mathrm{THF})_{3} 1.39 \mathrm{~g}$ $(3.70 \mathrm{mmol})$ in $45 \mathrm{~mL}$ of $\mathrm{THF}$ at $-78{ }^{\circ} \mathrm{C}$. The mixture was stirred overnight. The color of the reaction mixture changed from purple to blue then to dark blue. After the solvent was removed under vacuum, toluene was added to precipitate $\mathrm{LiCl}$, and the organic layer was concentrated to $30 \mathrm{~mL}$. At low temperature, $145 \mathrm{mg}$ dark blue needle crystals were obtained in 12.6\% yield. EI-MS (m/e): 335 (67, M), 299 (100, M-Cl), 261 (51, M-2Cl). IR (cm , KBr): 3107 m, 2934 s, 2856 m, 1656 w, 1637 w, 1623 w, 1496 m, 1461 m, 1409 m, 1223 w, 1198 w, 1156 m, 1114 w, 1074 w, 1046 w, 1012 m, 936 w, 885 w, 830 s, 748 s, 598 s, 503 s, 423 s. Calc. for $\mathrm{C}_{12} \mathrm{H}_{13} \mathrm{Cl}_{2} \mathrm{CrS}=310.95: \mathrm{C}, 46.17 \% ; \mathrm{H}, 4.20 \%$. Found: $\mathrm{C}, 45.91 \% ; \mathrm{H}, 4.23 \%$.

\subsection{Polymerization Procedure}

A $50 \mathrm{~mL}$ flask equipped with an ethylene inlet, magnetic stirrer, and vacuum line. The flask was filled with proper volume of freshly distilled solvent. MAO was added, and the flask was placed in a bath at the desired polymerization temperature for $10 \mathrm{~min}$. The polymerization reaction was started by adding a solution of the catalyst precursor with a syringe. The polymerization was carried out for $30 \mathrm{~min}$ and then quenched with $3 \% \mathrm{HCl}$ in ethanol $(50 \mathrm{~mL})$. The precipitated polymer was filtered and then dried overnight in a vacuum oven at $80{ }^{\circ} \mathrm{C}$. ${ }^{1} \mathrm{H}-\mathrm{NMR}$ spectra were recorded on a Varian GRMINI-400 spectrometer (Fitchburg, MA, USA) in 1,2-dichlorobenzene at $100{ }^{\circ} \mathrm{C}$. Molecular weight and molecular weight distribution $\left(M_{\mathrm{w}} / M_{\mathrm{n}}\right)$ values were obtained from Waters-208 LC/GPC chromatograms (Milford, MA, USA) employing polystyrene standards for calibration. Analysis was carried out by using 1,2-dichlorobenzene at high temperature $\left(140^{\circ} \mathrm{C}\right)$. 


\section{Conclusions}

A series of novel oxygen or sulfur functionalized cyclopentadienylchromium complexes were prepared and characterized. In the presence of MAO, these complexes show moderate to high activities in catalyzing ethylene polymerization and afford high molecular weight polymers. The electronic properties and steric hindrances of the substituents of the ligands remarkably affect the catalytic activities of these complexes, and complex 7 with the thiofuryl substituted cyclopentadienyl ring of the ligand exhibits the highest activity among them. The highest activity for ethylene polymerization was achieved as $1.96 \times 10^{6} \mathrm{~g} \mathrm{PE} / \mathrm{mol} \mathrm{Cr} \cdot \mathrm{h}$ by complex 7 . These results and the easy modification feature of these complexes are helpful in developing efficient catalysts which have potential industrial applications.

Supplementary Materials: Supplementary Materials are available online. The figure of the infrared spectra of comparison of complex 1 and ligand 1a; the ${ }^{1} \mathrm{H}-\mathrm{NMR}$ spectrum of typical polymer obtained with 7/MAO (entry 16).

Acknowledgments: This work was financially supported by the National Science Foundation of China (No. 21364005), the National Science Foundation of Inner Mongolia (No. 2017MS0206 and 2016MS0218), Grassland Talent Innovative Teams of Inner Mongolia Autonomous Region and the project was supported by Open Research Fund of State Key Laboratory of Polymer Physics and Chemistry, Changchun Institute of Applied Chemistry, Chinese Academy of Sciences.

Author Contributions: Hao Zhang and Jiling Huang conceived and designed the experiments. Ruiguo Zhao, Jun Ma, and Hao Zhang performed the experiments. Ruiguo Zhao, Hao Zhang, and Jiling Huang analyzed the data. Ruiguo Zhao and Hao Zhang wrote the manuscript.

Conflicts of Interest: The authors declare no conflict of interest.

\section{References}

1. Brintzinger, H.H.; Fisher, D.; Mulhaupt, R.; Rieger, B.; Waymouth, R.M. Stereospecific Olefin Polymerization with Chiral Metallocene Catalysts. Angew. Chem. Int. Ed. Engl. 1995, 34, 1143-1170. [CrossRef]

2. Gibson, V.C.; Spitzmesser, S.K. Advances in Non-Metallocene Olefin Polymerization Catalysis. Chem. Rev. 2003, 103, 283-316. [CrossRef] [PubMed]

3. Qian, Y.L.; Huang, J.L.; Bala, M.D.; Lian, B.; Zhang, H.; Zhang, H. Synthesis, Structures, and Catalytic Reactions of Ring-Substituted Titanium(IV) Complexes. Chem. Rev. 2003, 103, 2633-2690. [CrossRef] [PubMed]

4. Redshaw, C.; Tang, Y. Tridentate ligands and beyond in group IV metal a-olefin homo-/co-polymerization catalysis. Chem. Soc. Rev. 2012, 41, 4484-4510. [CrossRef] [PubMed]

5. Baier, M.C.; Zuideveld, M.A.; Mecking, S. Post-Metallocenes in the Industrial Production of Polyolefins. Angew. Chem. Int. Ed. 2014, 53, 9722-9744. [CrossRef] [PubMed]

6. Hogan, J.P.; Banks, R.L. Polymers and Production thereof. U.S. Patent 2,825,721, 4 March 1958.

7. Karol, F.J.; Karapinka, G.L.; Wu, C.; Dow, A.W.; Johnson, R.N.; Carrick, W.L. Chromocene catalysts for ethylene polymerization: Scope of the polymerization. J. Polym. Sci. 1972, 10, 2621-2637. [CrossRef]

8. Karapinka, G.L. Polymerization of Ethylene Using Supported bis-(Cyclopentadienyl)chromium(II)catalysts. U.S. Patent 3,709,853, 9 January 1973.

9. Theopold, K.H. Homogeneous Chromium Catalysts for Olefin Polymerization. Eur. J. Inorg. Chem. 1998, 131, 15-24. [CrossRef]

10. Döhring, A.; Göhre, J.; Jolly, P.W. Donor-Ligand-Substituted Cyclopentadienylchromium(III) Complexes: A New Class of Alkene Polymerization Catalyst. 1. Amino-Substituted Systems. Organometallics 2000, 19, 388-402. [CrossRef]

11. Ikeda, H.; Monoi, T.; Ogata, K.; Yasuda, H. Ethylene Polymerizations with Alkyl-, Disilylamino- and Cyclopentadienylchromium/MMAO Initiators. Macromol. Chem. Phys. 2001, 202, 1806-1811. [CrossRef]

12. Enders, M.; Fernández, P.; Ludwig, G.; Pritzkow, H. New Chromium(III) Complexes as Highly Active Catalysts for Olefin Polymerization. Organometallics 2001, 20, 5005-5007. [CrossRef]

13. Ogata, K.; Nakayamay, Y.; Yasuda, H. Homopolymerizations and Random Copolymerizations of Olefins with Amino-Substituted Cyclopentadienylchromium Complexes. J. Polym. Sci. 2002, 40, 2759-2771. [CrossRef]

14. Döhring, A.; Jensen, V.R.; Jolly, P.W.; Thiel, W.; Weber, J.C. Donor-Ligand-Substituted Cyclopentadienylchromium(III) Complexes: A New Class of Alkene Polymerization Catalyst. 2. PhosphinoalkylSubstituted Systems. Organometallics 2001, 20, 2234-2245. [CrossRef] 
15. Liang, Y.F.; Yap, G.P.A.; Rheingold, A.L. Constrained Geometry Chromium Catalysts for Olefin Polymerization. Organometallics 1996, 15, 5284-5286. [CrossRef]

16. Randoll, S.; Jones, P.G.; Tamm, M. Chromium Complexes with $\mathrm{Me}_{2}$ Si-Bridged Cyclopentadienylimidazolin-2-imine Ligands: Synthesis, Structure, and Use in Ethylene Polymerization Catalysis. Organometallics 2008, 27, 3232-3239. [CrossRef]

17. Xu, J.S.; Mu, X.Y.; Zhang, Y.T.; Su, Q.; Ni, J.G.; Mu, Y. Constrained geometry nitrogen-functionalised diphenylcyclopentadienyl chromium(III) complex: Synthesis, structure and catalytic properties for ethylene polymerisation. J. Chem. Res. 2006, 552-554. [CrossRef]

18. Voges, M.H.; Romming, C.; Tilset, M. Synthesis and Characterization of 14-Electron Cyclopentadienyl Chromium(II) Complexes Containing a Heterocyclic Carbene Ligand. Organometallics 1999, 18, 529-533. [CrossRef]

19. Rogers, J.S.; Bazan, G.C. Oligomerization-transmetallation reactions of $\mathrm{Cp}^{*} \mathrm{CrMe}\left(\mathrm{PMe}_{3}\right) /$ methylaluminoxane catalysts. J. Chem. Soc. Chem. Commun. 2000, 13, 1209-1210. [CrossRef]

20. Messere, R.; Spirlet, M.R.; Jan, D. Preparation, characterization and crystal structure of the dinuclear chromium complex $\left\{\left(\mathrm{C}_{5} \mathrm{H}_{5}\right) \mathrm{Cr}\left[\mu-\mathrm{CH}_{2} \mathrm{SiMe}_{2}-\mathrm{N}\left(\mathrm{SiMe}_{3}\right)\right]\right\}_{2}$. Eur. J. Inorg. Chem. 2000, 6, 1151-1153. [CrossRef]

21. Bazan, G.C.; Rogers, J.S.; Fang, C.C. Catalytic insertion of ethylene into Al-C bonds with pentamethylcyclopentadienyl-chromium(III) complexes. Organometallics 2001, 20, 2059-2064. [CrossRef]

22. Sieb, D.; Baker, R.W.; Wadepohl, H.; Enders, M. Naphthyridine Cyclopentadienyl Chromium Complexes as Single-Site Catalysts for the Formation of Ultrahigh Molecular Weight Polyethylene. Organometallics 2012, 31, 7368-7374. [CrossRef]

23. Zhang, L.; Gao, W.; Tao, X.; Wu, Q.L.; Mu, Y.; Ye, L. New Chromium(III) Complexes with Imine-Cyclopentadienyl Ligands: Synthesis, Characterization, and Catalytic Properties for Ethylene Polymerization. Organometallics 2011, 30, 433-440. [CrossRef]

24. Ronellenfitsch, M.; Gehrmann, T.; Wadepohl, H.; Enders, M. Improving 1-Hexene Incorporation of Highly Active Cp-Chromium-Based Ethylene Polymerization Catalysts. Macromolecules 2017, 50, 35-43. [CrossRef]

25. Zhang, H.; Ma, J.; Qian, Y.L.; Huang, J.L. Synthesis and Characterization of Nitrogen-Functionalized Cyclopentadienylchromium Complexes and Their Use as Catalysts for Olefin Polymerization. Organometallics 2004, 23, 5681-5688. [CrossRef]

26. Qian, Y.L.; Huang, J.L. Novel intramolecular coordination chemistry of some new metallocene complexes. Chin. J. Chem. 2001, 19, 1009-1022. [CrossRef]

27. Qian, Y.; Huang, J.; Yang, J.; Chan, A.S.C.; Chen, W.; Chen, X.; Li, G.; Jin, X.; Yang, Q. Syntheses, structures and reactions of some new benzyl-substituted cyclopentadienyl titanium complexes. J. Organomet. Chem. 1997, 547, 263-279. [CrossRef]

28. Qian, Y.L.; Zhang, H.; Huang, J.L. Synthesis and Characterization of Cyclopentadienylchromium Complexes Bearing a Pendant o- $\mathrm{Me}_{2} \mathrm{~N}-\mathrm{C}_{6} \mathrm{H}_{4}-\mathrm{C}\left(\mathrm{CH}_{3}\right)\left(\mathrm{CH}_{3}\right)$-Group as Catalysts for Ethylene Polymerization. Chin. J. Catal. 2003, 24, 487-488.

29. Huang, J.; Wang, C.; Qian, Y. Ethylene trimerization with a half-sandwich titanium complex bearing a pendant thienyl group. Chem. Commun. 2003, 22, 2816-2817. [CrossRef]

30. Ye, W.-P.; Mu, H.-L.; Shi, X.-C.; Cheng, Y.-X.; Li, Y.-S. Synthesis and characterization of the titanium complexes bearing two regioisomeric trifluoromethyl-containing enaminoketonato ligands and their behavior in ethylene polymerization. Dalton Trans. 2009, 43, 9452-9465. [CrossRef] [PubMed]

31. Makio, H.; Terao, H.; Iwashita, A.; Fujita, T. FI Catalysts for Olefin Polymerization-A Comprehensive Treatment. Chem. Rev. 2011, 111, 2363-2449. [CrossRef] [PubMed]

32. Huang, W.; Sun, W.-H.; Redshaw, C. 2-(1-(Arylimino)propyl)quinolin-8-olate half-titanocene dichlorides: Synthesis, characterization and ethylene (co-)polymerization behaviour. Dalton Trans. 2011, 40, 6802-6809. [CrossRef] [PubMed]

33. Francis, P.S.; Cooke, R.C.; Elliott, J.H. Fractionation of polyethylene. J. Polym. Sci. 1958, 31, 453-466. [CrossRef]

Sample Availability: Samples of the compounds are available from the authors. 